\title{
Preparation and Characterization of Solid Dispersion Telmisartan - Hydroxypropyl Methyl Cellulose(HPMC) E5 LV by Co-Grinding Method
}

\author{
ERIZAL ZAINI*, LILI FITRIANI, SANEZEA EFFENDY, \\ DENI NOVIZA and AUZAL HALIM
}

Department of Pharmaceutics, Andalas University, Kampus Limau Manis, Padang, 25163, Indonesia.

*Corresponding author E-mail: erizal@ffarmasi.unand.ac.id

http://dx.doi.org/10.13005/ojc/330236

(Received: October 14, 2016; Accepted: January 02, 2017)

\begin{abstract}
Telmisartan (TMS), an antihypertensive drug, is classified as class II according to Biopharmaceutical Classification System (BCS) with low solubility and high permeability. The purpose of this study was to prepare and characterize solid dispersion of TMS with hidroxypropyl methyl cellulose (HPMC) E5 LV to increase the solubility. Solid dispersion was prepared in three different ratio TMS:HPMC 2:1, 1:1, and 1:2 (w/w) by co-grinding method for 60 minutes. Solubility test was conducted in distilled water for 72 hours and the amount of TMS was determined by spectrophotometry UV. Result of Powder X-Ray Diffraction (PXRD) showed a decrease in intensity of TMS in accordance with the amount of HPMC E5 LV in solid dispersion. Fourier Transform Infra-Red(FT-IR)Spectra showed no significant shift of wavelength. Scanning Electron Microscopy (SEM) result presented the crystalline form of TMS, while both physical mixture and solid dispersion at different ratio showed TMS stick on the surface of HPMC E5 LV. Thermogram of Differential Scanning Calorimetry (DSC) showed an incline of endotherm peak as the ratio HPMC E5 LV increased. The solubility result of intact TMS was $0.49 \pm 0.03 \mu \mathrm{g} / \mathrm{mL}$, while the physical mixture and solid dispersion $2: 1,1 ; 1$ and $1: 2$ were $1.87 \pm 0.18 \mu \mathrm{g} / \mathrm{mL}, 5.36 \pm 0.48 \mu \mathrm{g} / \mathrm{mL}, 7.24 \pm 1.73 \mu \mathrm{g} / \mathrm{mL}$, and $14.89 \pm 1.49 \mu \mathrm{g} / \mathrm{mL}$, respectively. In conclusion, solid dispersion of telmisartan-HPMC E5 LV enhanced the solubility of TMS.
\end{abstract}

Keywords: Telmisartan, HPMC E5 LV, Solid dispersion, Solubility, co-grinding.

\section{INTRODUCTION}

Telmisartan (TMS), an antihypertensive drug, belongs to angiotensin receptor blockers (ARBs) which act by inhibiting receptor stimulation of angiotensin II type 1 (AT1) without affecting other related receptors in cardiovascular ${ }^{1}$. TMS is classified as class II, low solubility high permeability, based on Biopharmaceutical Classification System (BCS). The main problem is the low solubility of drugs in biological fluids that result in poor bioavailability after oral administration ${ }^{2}$. Therefore, it is necessary to improve the solubility and dissolution rate of TMS. Several studies have been conducted to improve 
the solubility and dissolution of TMS including co-grinding TMS with polyvinyl alcohol ${ }^{3}$, formation of solid nanoparticles ${ }^{4}$, inclusion complex of TMS and $\beta$-cyclodextrins ${ }^{5}$, formation of cocrystalline phase with several coformers ${ }^{6,7}$, formation amorphous solid dsipersion ${ }^{8}$.

Various strategies are used to increase the solubility and dissolution rate of drugs BCS class II and solid dispersion is one of effective approaches ${ }^{9,10}$. This method can be defined as a molecular dispersion of active substance in one or more hydrophilic carriers, which involved a reduction in particle size, increase the wettability of the active ingredient by the carrier, the formation of soluble complexes, and the formation of an amorphous active substance. In the solid dispersion, the hydrophilic polymer also plays an important role in inhibiting the crystallization of crystalline phase through the process of molecular mobility ${ }^{11,12}$.

In this research, preparation of solid dispersions TMS - HPMC E5 LV using a planetary ball mill with a ratio of $2: 1,1: 1,1: 2(\mathrm{w} / \mathrm{w})$ aimed to modify the solid properties of TMS and the effects on the solubility. The results obtained were then characterized by Scanning electron microscope (SEM), analysis of X-ray diffraction, differential scanning calorimetry (DSC), Fourier Transform Infrared spectroscopy (FT-IR), and solubility test.

\section{MATERIALS and METHODS}

Telmisartan (TMS) (Dr. Reddy's Laboratories, India), HPMC E5 LV (Wuhan Senwayer, China), $\mathrm{KH}_{2} \mathrm{PO}_{4}$ (Bratachem, Indonesia), $\mathrm{NaOH}$ and distilled water. All materials were used as received.

\section{Preparation of solid dispersion}

Preparation of solid dispersion TMS and HPMC E5LV was conducted using co-grinding method in a planetary ball mill (Fritsch, Pulverissete 7, Germany) at $500 \mathrm{rpm}$. Solid dispersion was prepared at three ratio of TMS:HPMC E5 LV 2:1, $1: 1$ and $1: 2(w / w)$ and grounded for 60 minutes. The milled powder then was kept in a desiccator.

\section{Preparation of physical mixture}

Preparation of physical mixture was done at ratio of TMS:HPMC E5 LV 1:1 (w/w). The mixture was mixed homogenously in a sealed container and the mixed powder then was also kept in a desiccator.

\section{Powder X-Ray Diffraction Analysis}

Intact TMS, intact HPMC E5 LV, physical mixture and solid dispersion at different ratio were analyzed the crystallinity degree using an X-ray diffractometer (X'Pert XRD Powder type PW 30/40 PANalytical, The Netherlands). Samples were placed on the sample holder and levelled to prevent particle orientation during sample preparation. Analysis was carried out at $2 \Theta$ range $5-40^{\circ}$. Measurement condition was as follow: target metals $\mathrm{Cu}, \mathrm{K} \alpha$ filter, voltage $45 \mathrm{kV}$, and current $40 \mathrm{~mA}$.

\section{Scanning Electron Microscopy (SEM) analysis}

Sample powder was placed on an aluminum sample holder and the voltage was set at $10 \mathrm{kV}$ and current $12 \mathrm{~mA}$ to observe surface and morphology of TMS and HPMC E5 LV before and after mixing and co-grinding. Sample was observed on various magnifications using SEM (HITACHI type S-3400N, Japan). SEM analysis was done for intact TMS, intact HPMCE5LV, physical mixture and solid dispersions at all ratio.

\section{FT-IR spectroscopy analysis}

FT-IR spectroscopy analysis was done using a PerkinEImer FT-IR Spectrophotometer, where the samples absorption spectra were recorded at wave number $4000-400 \mathrm{~cm}^{-1}$ in order to observe and confirm the functional groups and fingerprint of each sample. FT-IR spectroscopy analysis was done for intact TMS, intact HPMC E5 LV, physical mixture and solid dispersions at all ratio.

\section{Differential Scanning Calorimetry}

The thermal properties of intact TMS, intact HPMC E5 LV, physical mixture and solid dispersions at all ratio were determined using a thermal analyzer (Mettler Toledo FP90, Switzerland) which has been calibrated with Indium temperature. Each sample in a small amount was placed on an aluminum pan and the instrument temperature was set in a range from $50^{\circ} \mathrm{C}$ to $300^{\circ} \mathrm{C}$ at $10^{\circ} \mathrm{C}$ per minute of heating rate.

\section{Solubility test}

An excessive amount intact TMS, physical mixture and solid dispersions at all ratio were dissolved in $100 \mathrm{~mL}$ of distilled water. Solubility test 
was conducted for 72 hours in an orbital shaker at room temperature. Samples were analyzed using UV spectrophotometer (Shimadzu UV-1700, Japan) at the wavelength of TMSmaximum absorption 295.2 $\mathrm{nm}$. All experiments were done triplicated.

\section{RESULTS and DISCUSSIONS}

\section{Powder X-Ray Diffraction Analysis}

The diffractogram of intact TMS, intact HPMC E5 LV, physical mixture, and solid dispersions can be seen in Figure 1. Intact TMS showed the sharp peak indicated its form as crystalline, while HPMC E5 LV showed an amorphous phase as no sharp peak observed due to HPMC E5 LV is a hydrophilic polymer. The physical mixture showed a decrease of peak intensity. In addition, the greater the amount of HPMC E5 LV, the greater decrease of peak intensity in solid dispersion. Solid phase changes of telmisartan was occured during co-grinding process such as partial amorphization.
The position of $2 \theta$ and intensity of the peak for intact TMS, physical mixture and solid dispersion at all ratio is shown in Table 1. This result indicated that preparation of solid dispersion at all ratio give an impact in decreasing the TMS crystallinity, which decrease the rigidity of TMS and likely increase the solubility ${ }^{11}$. Solid dispersion at 1:2 showed the greatest reduction of peak intensity at $2 \Theta(14.1781$, 15.0101, 22.2641 and 24.9421) which decrease 4.7; 2.5; 3.4; and 2.6 fold, respectively.

\section{Scanning Electron Microscopy Analysis}

The morphology of intact TMS, intact HPMC E5 LV, physical mixture, and solid dispersions all ratio is shown in Figure 2. TMS looked like needles in crystalline form, while HPMC E5 LV looked like a fiber. The physical mixture of TMS - HPMC E5 LV and solid dispersion depicted that TMS was on the surface of HPMC E5 LV, but the difference in morphology among them could not be distinguished based on SEM result. In solid dispersion system,

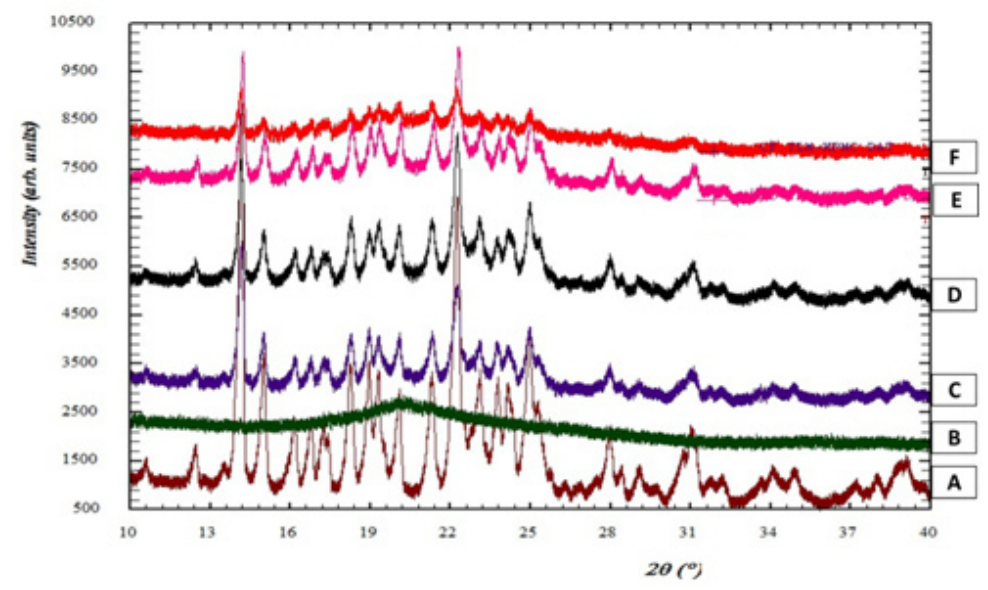

Fig. 1: Diffractogram of (A) TMS, (B) HPMC E5LV, (C) Physical Mixture, (D) Solid Dispersion 2:1, (E) Solid Dispersion 1:1, and (F) Solid Dispersion 1:2

Table 1: Peak intensity of TMS, physical mixture and solid dispersions

\begin{tabular}{lccccc}
\hline $\begin{array}{l}\text { Position } \\
\text { (29) }\end{array}$ & $\begin{array}{c}\text { Intact } \\
\text { telmisartan }\end{array}$ & $\begin{array}{c}\text { Physical } \\
\text { mixture } \\
\mathbf{1 : 1}\end{array}$ & $\begin{array}{c}\text { Solid } \\
\text { dispersion } \\
\mathbf{2 : 1}\end{array}$ & $\begin{array}{c}\text { Solid } \\
\text { dispersion } \\
\mathbf{1 : 1}\end{array}$ & $\begin{array}{c}\text { Solid } \\
\text { dispersion } \\
\mathbf{1 : 2}\end{array}$ \\
\hline & & & & & \\
14.1781 & 8713.11 & 3905.11 & 3625.59 & 3471.25 & 2051.43 \\
15.0101 & 3623.26 & 2032.64 & 2157.86 & 2084.26 & 1449.26 \\
22.2641 & 6801.54 & 3011.58 & 4138.31 & 3675.67 & 2014.06 \\
24.9421 & 4090.83 & 2112.23 & 2659.64 & 2307.47 & 1589.82 \\
\hline
\end{tabular}


fine particles of TMS embedded on HPMC E5 LV, a hydrophilic carrier, and, LV, and contributed to the improvement solubility of TMS. Thus, solid dispersion of TMS in a hydrophilic carrier increase wettability TMS.

\section{FT-IR Spectroscopy Analysis}

The FT-IR spectra of intact TMS, intact HPMC E5 LV, physical mixture and solid dispersion is shown in Figure 3. TMS showed the $\mathrm{OH}$ strain at wavenumber $3047.63 \mathrm{~cm}^{-1}$ from carboxylic acid and $\mathrm{C}-\mathrm{H}$ aliphatic strain at wave number $2939.80 \mathrm{~cm}^{-1}$. On the other hand, wave length of HPMC E5 LV for OH strain was at $3400.43 \mathrm{~cm}^{-1}$ and $\mathrm{C}-\mathrm{H}$ aliphatic strain were $2902.97 \mathrm{~cm}^{-1}, 1590.77 \mathrm{~cm}^{-1}$ and $1046.36 \mathrm{~cm}^{-1}$. There was a shift wave numbers of $\mathrm{OH}$ strain
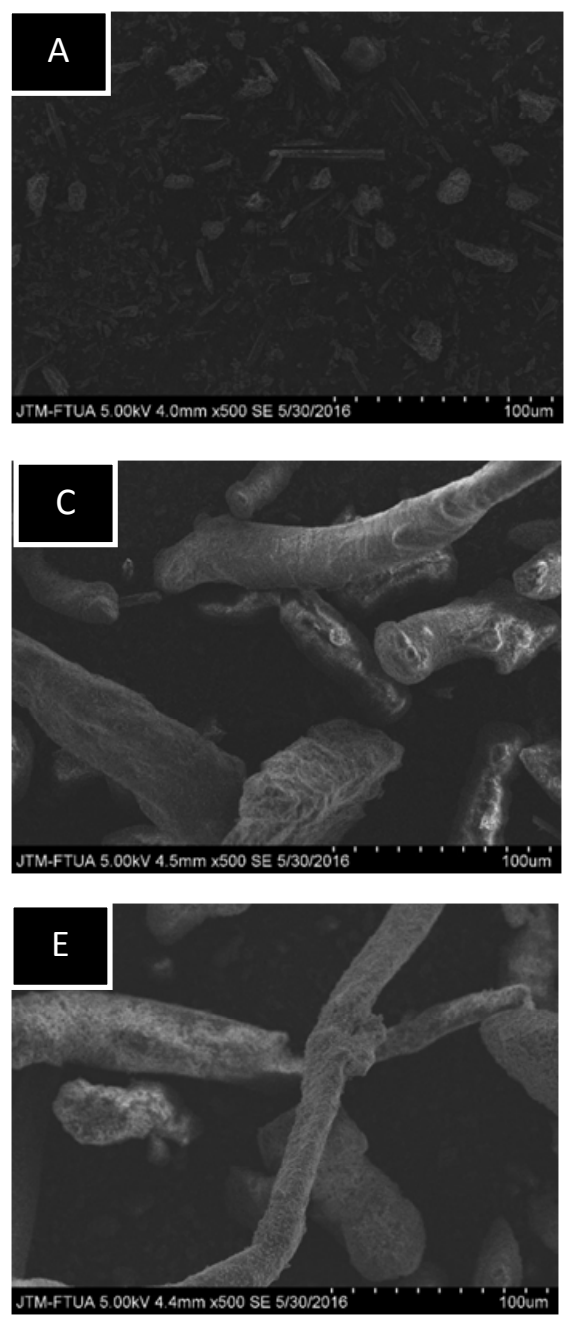

from carboxylic acidat $3045.61 \mathrm{~cm}^{-1} ; 2881.97 \mathrm{~cm}^{-1}$; $2879.97 \mathrm{~cm}^{-1}$; and $2878.99 \mathrm{~cm}^{-1}$ for physical mixture and solid dispersion $1: 2 ; 1: 1 ; 2: 1$, respectively. This wavelength shift was still within the range of strain $\mathrm{OH}$. Moreover, shift wave number of $\mathrm{C}-\mathrm{H}$ aliphatic group of physical mixture and solid dispersion 1 : 2; 1: 1; 2: 1 were at $2953.03 \mathrm{~cm}^{-1} ; 2959.22 \mathrm{~cm}^{-1}$; $2959.21 \mathrm{~cm}^{-1}$; and $2960.61 \mathrm{~cm}^{-1}$, respectively. Thus, there was no new functional group observed which indicated no chemical interaction occurred between TMS and HPMC E5 LV in both physical mixture and solid dispersion at all ratio. This result was anticipated since the preparation of solid dispersion was not purposed to produce new substance, yet to modify the physicochemical properties ${ }^{13}$.
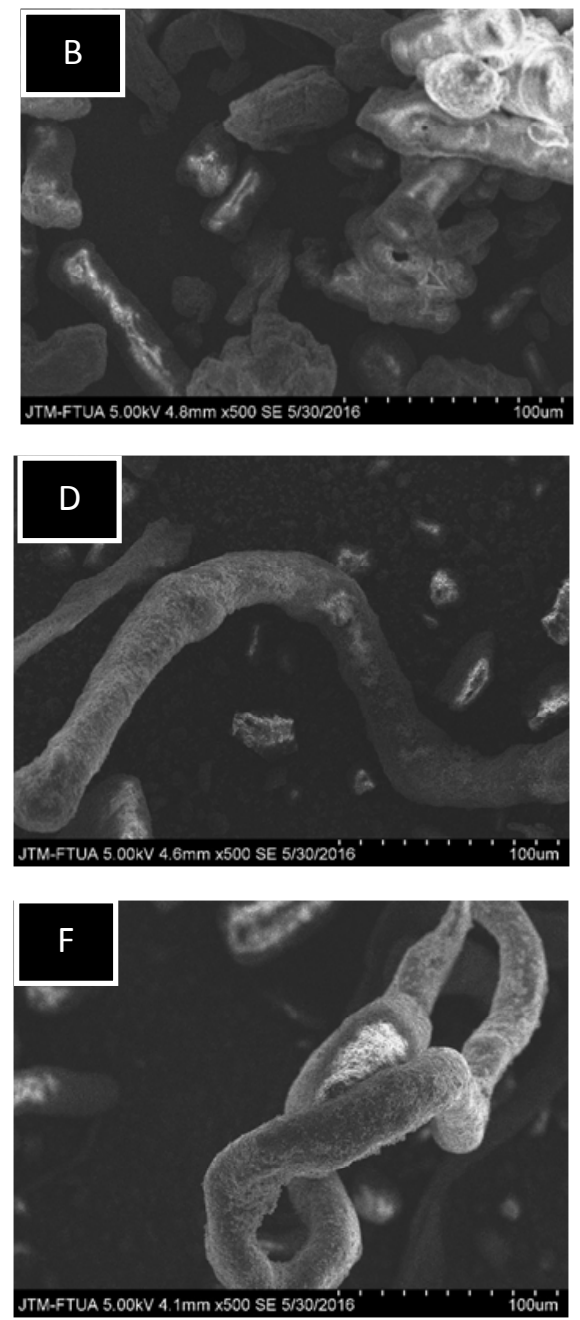

Fig. 2: Scanning Elctrom Microscopy of (A) TMS, (B) HPMC E5 LV, (C), Physical Mixture, (D) Solid Dispersion 2:1, (E) Solid Dispersion 1:1, and (F) Solid Dispersion 1:2 
Differential Scanning Calorimetry (DSC) Analysis

Thermal properties of intact TMS, intact HPMC E5 LV, physical mixture and solid dispersion at all ratio can be seen in Figure 4. Based on DSC thermogram, TMS showed a sharp endothermic peak $\left(T_{\text {peak }} 268.96^{\circ} \mathrm{C}\right)$ Corresponding to its melting event, indicating its crystallinity phase. Meanwhile, DSC thermogram of HPMC E5 LV showed a broad endothermic peak in the range $95.96^{\circ} \mathrm{C}$, which may be attributed to dehydration of water molecules. The physical mixture and solid dispersions showed two peaks which represented TMS and HPMC E5 LV. Based on the thermogram data, there was a decrease of TMS melting point. The melting point of TMS in physical mixture was $267.54^{\circ} \mathrm{C}$ while at solid dispersions $2: 1,1: 1$ and $1: 2$ were $268.41^{\circ} \mathrm{C}$, $267.47^{\circ} \mathrm{C}$ and 266.90 , respectively. This result is in accordance with PXRD result, where the solid dispersion at 1:2 showed the lowest peak intensity3,9.

Table 2: Result of solubility test

\begin{tabular}{lcc}
\hline Materials & $\begin{array}{c}\text { Solubility } \\
(\mu \mathrm{g} / \mathrm{ml})\end{array}$ & $\begin{array}{c}\text { Enhancement } \\
\text { of solubility }\end{array}$ \\
\hline Intact TMS & $0.49 \pm 0.03$ & - \\
Physical mixture & $1.87 \pm 0.18$ & 3.8 fold \\
Solid dispersion 2:1 & $5.36 \pm 0.48$ & 10.9 fold \\
Solid dispersion 1:1 & $7.24 \pm 1.73$ & 14.7 fold \\
Solid dispersion 1:2 & $14.89 \pm 1.49$ & 30.3 fold \\
\hline
\end{tabular}

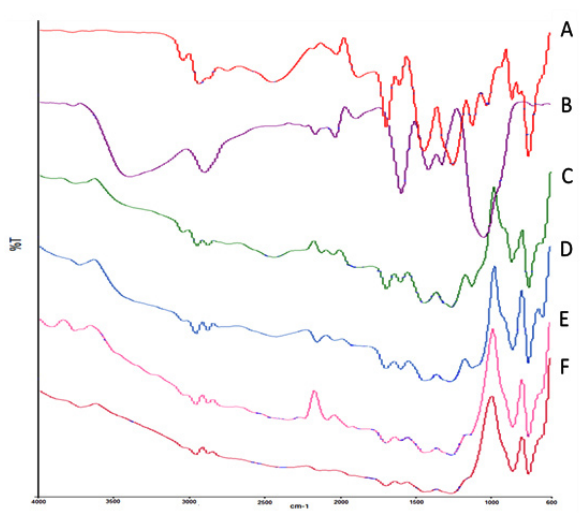

Fig. 3: FT-IR Spectra of (A) TMS, (B) HPMC E5 LV, (C), Physical Mixture,

(D) Solid Dispersion 1:2, (E) Solid Dispersion 1:1, and (F) Solid Dispersion 2:1
However, the characteristic endothermic peak corresponding to drug melting point was broadened and shifted toward lower temperature with reduced intensity.

\section{Solubility test}

The result of solubility test can be seen in Table 2. There was a trend observed as the increasing the amount of HPMC E5 LV, the solubility of TMS increased significantly $(P<0.05)$. Moreover, the solubility of physical mixture was also increased. This result is in accordance with the PXRD and DSC analysis. As the crystallinity degree of TMS decreased, the solubility of TMS increased. In addition, the mechanism of HPMC E5 LV on increasing solubility was also due to the intrinsic characteristic of HPMC as the hydrophilic polymer which soluble in the water ${ }^{10,11,12}$. Mechanical energy supplied during co-grinding process TMS HPMC E5 LV in a planetary ball mill apparatus may cause crystalline phase of TMS underwent partial amorphization and TMS dispersed in a hydrophilic polymer network in the form of fine particles ${ }^{14}$. Thus, the dominant factors affecting drug dissolution from the co-grinding particles were the reduction of drug crystallinity, a probable decrease in drug particle size, an increase in the de-aggregation and wettability of hydrophobic drug particles. Similar observations have been reported for mebendazole and norfloxacin where the solubility of this poorly water soluble was improved by high wettability and reduction of drug crystallinity ${ }^{15-16}$.

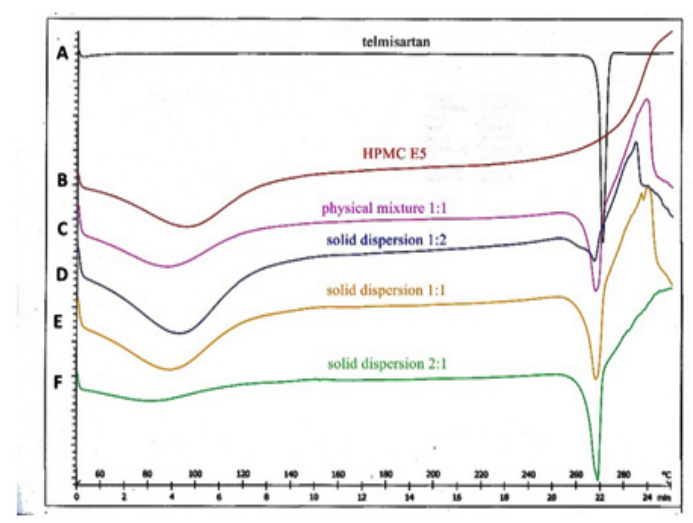

Fig. 4: Thermogram DSC of (A) TMS, (B) HPMC E5 LV, (C) Physical Mixture, (D) Solid Dispersion 1:2, (E) Solid Dispersion 1:1, and (F) Solid Dispersion 2:1 


\section{CONCLUSION}

In the conclusion, the co-grinding method was successfully applied to prepare solid dispersions of telmisartan with hydrophilic polymer HPMC E5 LV. Solid dispersions of TMS with HPMC E5 LV has higher solubility than intact TMS and its physical mixture. The enhancement of the solubility may be due to partial amorphization of TMS crystalline phase.

\section{ACKNOWLEDGMENT}

The authors would like to thank for research granted by Hibah Klaster Guru Besar Andalas University No 17/UN.16/HKRGB/LPPM/2016. The authors also thank Mr. Mulyadi Sirin from PT. Tata Rasa Primatama for providing TMS in this research.

\section{REFERENCES}

1. Sharpe, M.; Jarvis, B.;\& Goa, K. L. Drugs, 2001, 61(10), 1501-1529.

2. Marasini, N.; Tran, T. H.; Poudel, B. K.; Cho, H. J.; Choi, Y. K.; Chi, S. C.; Choi, H.G.; Yong C.S.\& Kim, J. O. Int. J. Pharm., 2013, 441(1), 424-432.

3. Isaac, J.; Ganguly, S. \& Ghosh, A. Eur. J. Pharm. Biopharm., 2016, 101, 43-52.

4. Patel, J.; Dhingani, A.; Garala, K.; Raval, M. \& Sheth, N. Powder Technol., 2014, 258, 331343.

5. Borba, P. A. A.; Pinotti, M.; Andrade, G. R. S.; da Costa, N. B.; Olchanheski, L. R.; Fernandes, D.; de Campos, C.E.M.\& Stulzer, H. K. Carbohydr. Polym., 2015, 133, 373383.

6. Alatas, F.; Ratih, H.\& Soewandhi, S. N. Int. J. Pharm. Pharm. Sci., 2015, 7(3), 423-426.

7. Chadha, R.; Bhandari, S.; Haneef, J.; Khullar, S. \& Mandal, S. Cryst.Eng.Comm, 2014, 16(36), 8375-8389.

8. Dukeck, R.; Sieger, P.; \& Karmwar, P. Eur. J.
Pharm. Sci., 2013, 49(4), 723-731.

9. Fitriani, L.; Haqi, A.\& Zaini, E. J. Adv. Pharm. Tech. Res, 2016, 7(3), 105.

10. Leuner, C. \& Dressman, J. Eur. J. Pharm. Biopharm., 2000, 50(1), 47-60.

11. Salman, Ardiansyah, Nasrul, E.; Rivai, H.; Ben, E. S.\& Zaini, E. Int. J. Pharm. Pharm. Sci., 2014, 7(2), 209-212.

12. Vasconcelos, T.; Sarmento, B. \& Costa, P. Drug Discovery Today, 2007, 12(23), 1068-1075.

13. Jamadar, S.; Pore, Y.\& Sayyad, F. Part. Sci. Technol., 2014, 32(5), 512-519.

14. Muehlenfeld, C.; Kann, B.; Windbergs, M. \& Thommes, M. J. Pharm. Sci., 2013, 102(11), 4132-4139.

15. García-Rodriguez, J. J.; Paloma, M.; VegasSánchez, M. C.; Torrado-Durán, S.; BolásFernández, F. \& Torrado-Santiago, S. Int. J.Pharm., 2011, 403(1), 23-28.

16. Loh, G. O. K.; Tan, Y.T. F. \& Peh, K. K. Powder Technol., 2014, 256, 462-469. 